\title{
Relato de experiência de dois estudantes de Geografia: teoria, prática e a vivência na escola através do Programa de Residência Pedagógica
}

Report from two Geography interns: theory, practice and the scholar experience through Pedagogical Internship Programme

Rafael da Rocha Lopez

Paula Vitória de Farias Santos

Renata Barrocas

Abigail Malavasi

Mariangela Camba

Patrícia Lopes Barboza

Resumo: Este relato de experiência apresenta as impressões de dois residentes do curso de Geografia no projeto multidisciplinar "Aprendendo e Ensinando significativamente - entrelaçando saberes e fazeres" desenvolvido pelo Programa de Residência Pedagógica na Universidade Metropolitana de Santos (UNIMES). A metodologia adotada foi a transcrição do relatório final e de um artigo apresentado em encontro científico referentes a participação dos residentes no programa. Os resultados apresentados indicam que os objetivos apresentados no projeto institucional foram alcançados com êxito. Os residentes consideraram que a participação no programa transformou a relação da teoria e prática que aprenderam na graduação com a realidade vivenciada na escola-campo.

Palavras-chave: Geografia. Programa de Residência Pedagógica. Estágio Supervisionado. Residentes.

\begin{abstract}
This report depicts the experience of two interns from the Geography course who took part of the crosscurricular project named ' Learning and Teaching substantially - linking knowledge and practices developed by the Pedagogical Internship Programme at Santos Metropolitan University Universidade Metropolitana de Santos (UNIMES). The methodology adopted was the transcription of the final report and an article presented in a scientific event referred to the participation of the interns in the programme. The results shows that the objectives presented in the institutional project succeeded. The residents concluded that their participation in the programme enhanced their theory-praxis relationship learned throughout their academic experience.
\end{abstract}

Keywords: Geography. Pedagogical Residency Programme. Supervised Internship. Interns.

\section{Introdução}

Este relato de experiência apresenta a vivência de dois estudantes da graduação em licenciatura de Geografia que participaram do Programa de Residência Pedagógica (PRP) organizado pelo Coordenação de Aperfeiçoamento de Pessoal de Nível Superior (CAPES) e que foi desenvolvida 
em uma unidade de ensino da rede municipal de São Vicente, SP. Os alunos foram contemplados com bolsa de participação no projeto e as observações e descrições abordados são resultados dos relatórios. As informações destes relatórios foram compiladas e sintetizadas pelas docentes orientadoras, coordenadora institucional e pela preceptora do projeto na escola-campo para a construção deste artigo.

A Universidade Metropolitana de Santos (UNIMES), localizada na região metropolitana da Baixada Santista, no estado de São Paulo, desenvolveu dois subprojetos durante a vigência de agosto de 2018 a janeiro de 2020, atendendo o calendário do edital 06/2018 da Capes. O relato dos estudantes diz respeito ao subprojeto multidisciplinar "Aprendendo e Ensinando significativamente - entrelaçando saberes e fazeres" que integrou quatro licenciaturas da instituição: Geografia, História, Matemática e Pedagogia. A sintonia entre residentes, docentes orientadores, preceptores e gestores da Secretaria de Educação de São Vicente promoveu momentos de produtividade permeados por ações criativas e reflexivas.

O aporte teórico deste subprojeto foi sustentado pelas ideias de autores que discutem a importância da aprendizagem significativa como Ausubel (2000) e Moreira (2011) além de atender os objetos de conhecimento da Base Nacional Comum Curricular de Geografia em conjunto com o plano de curso do componente na escola. O relato de experiência destes dois residentes tem uma relação direta com a apropriação destes documentos tanto no exercício da regência quanto na leitura e intepretação mediadas durante os meses de vivência na escola. Estes critérios de construção teórica foram organizados em concomitância ao conteúdo do Projeto Político Pedagógico do curso de Geografia e as orientações referentes ao estágio supervisionado.

Desde 2006, a licenciatura em Geografia da Unimes mantém suas atividades acadêmicas de pesquisa, ensino e extensão nas modalidades presencial e no ensino a distância (Ead). Atualmente, é o único curso de Geografia na Baixada Santista.

Através de atividades promovidas pelos calendários organizados durante os dezoito meses de projeto atingimos resultados que transformaram a leitura 
sobre o ambiente escolar entre os residentes. Para uma melhor organização e planejamento das ações pedagógicas no programa, organizamos cinco etapas de participação: grupo de formação dos residentes na Universidade; ambientação na escola-campo; regência; avaliação e socialização.

A proposta deste relato de experiência atende a uma necessidade de expor as impressões de dois residentes do PRP sob à luz da condução de suas percepções vivenciadas no processo. O conteúdo teórico e metodológico desenvolvido nas regências não atende a proposta deste relato. A intencionalidade deste material está direcionada para a discussão da interpretação do processo como um todo e o quanto este programa colaborou na compreensão do como se organiza a educação numa escola municipal e, sobretudo, quanto a importância do ensino de Geografia.

Vale destacar, que a Unimes continua participante das atividades do Programa de Residência Pedagógica no atual edital.

\section{Contexto do Programa de Residência Pedagógica e o subprojeto Multidisciplinar}

O Projeto Institucional de Residência Pedagógica da UNIMES teve duração de dezoito meses, distribuídos em dois meses para o curso de formação de preceptores e preparação dos alunos para o início das atividades; quatro meses de orientação conjunta (docentes orientadores e preceptores) com ambientação do residente na escola e elaboração do Plano de Atividade, com a exigência do mínimo de 60 (sessenta) horas na escola-campo; dez meses para a realização de 320 (trezentas e vinte) horas de imersão na escola, sendo no mínimo 100 (cem) horas destinadas à regência de classe, planejamento e execução de atividades, planos de aulas, sequências didáticas, projetos de ensino e atividades de avaliação da aprendizagem dos alunos; 02 (dois) meses para e elaboração do relatório final, avaliação e socialização dos resultados na escola, na universidade e na comunidade a partir da participação em eventos e publicação de artigos. Os eventos apresentados para a comunidade acadêmica e demais interessados ocorreram nos finais dos anos 
de 2018 e 2019. A distribuição das atividades atendeu o calendário proposto no edital pela Capes.

O objetivo geral deste subprojeto buscou promover o aperfeiçoamento da relação teoria e prática dos alunos no ambiente escolar e melhorar a qualidade dos cursos de formação de professores. Quanto aos objetivos específicos o propósito da Universidade foi integrar os currículos das escolascampo e a Base Nacional Comum Curricular (BNCC) dos componentes de Geografia, História, Matemática e Pedagogia adequando-os ao curso de formação de preceptores e residentes; promover a formação de preceptores e residentes, de acordo com o referencial teórico dos autores que discutem o conceito e aplicação da Aprendizagem Significativa no ambiente escolar, para que estes se tornem multiplicadores e desenvolver habilidades conhecimentos e ações - nos residentes e preceptores para a apropriação do conteúdo da Aprendizagem Significativa, da BNCC bem como para o estudo da realidade local em variadas escalas geográficas como a escola e o bairro.

O Projeto preliminar foi elaborado pelo Núcleo Docente Estruturante das Licenciaturas, docentes orientadores e coordenadora institucional a partir de um levantamento com os preceptores e representantes da rede de ensino em reunião promovida em uma das escolas-campo. O levantamento foi realizado por meio de entrevista semiestruturada com perguntas sobre a formação profissional, expectativas da Residência Pedagógica e sugestões de atividades. Em conjunto a esse processo foi realizada leitura com o propósito de articular os Projetos Pedagógicos dos Cursos de Licenciaturas de Geografia, História, Matemática e Pedagogia e a Base Nacional Comum Curricular com ênfase nos estágios supervisionados sustentados pelas ideias Passini (2010) e Giglio et al. (2011).

A preparação em grupo promoveu leitura e discussão de textos, painel integrado, dinâmicas de grupo, cine debate e análise de estudos de caso. A elaboração de oficinas pedagógicas, promoveu a discussão sobre os eixos centrais do subprojeto, estratégias e desdobramentos da Aprendizagem Significativa de acordo com Ausubel (2000), Moreira (2011) articulando-os aos 
Projetos Pedagógicos dos Cursos e a Base Nacional Comum Curricular, conforme já destacado.

O desenvolvimento das atividades formativas partiu dos grupos de estudos formados e auxiliaram na formação teórica dos docentes, atualizandoos em relação aos autores e as concepções educacionais.

A IES disponibilizou seus Laboratórios de Práticas Interdisciplinares com materiais de Geografia, História, Matemática e Pedagogia. Aos preceptores a Universidade disponibilizou durante todo processo o acesso à Biblioteca física e virtual para pesquisa e estudo.

A participação em atividades como Semana Acadêmica das Licenciaturas, Seminários e outros eventos culturais e científicos foram oferecidos aos residentes nas modalidades presencial e a distância. O acompanhamento foi contínuo com encontros semanais entre docentes orientadores e residentes.

Para organizarmos um instrumento de acompanhamento foi desenvolvido uma ficha de avaliação contendo os indicadores e respectivos descritores - aspectos teóricos, relação teoria e prática, processo analítico, habilidade prática, imagem e postura profissional, supervisão, aspectos éticos, comunicação e relacionamento grupal, assiduidade, pontualidade, cumprimento do planejamento. Esta ficha de acompanhamento e avaliação foi preenchida pelo residente, pelas docentes orientadoras e pelo preceptor para os devidos ajustes em dois momentos do processo.

Os residentes desenvolveram relatórios que foram encaminhados aos professores na Universidade e discutidos com os preceptores. O acompanhamento se deu também para a preparação dos relatórios e de publicação científica promovido no II Encontro do Programa de Residência Pedagógica da Unimes no final do ano de 2019. A avaliação foi contínua e processual tanto nos encontros de supervisão como durante a permanência na escola.

A socialização e divulgação dos resultados a partir dos modelos de relatórios indicados pela Capes foram realizadas por meio da apresentação do relatório final do PRP na escola-campo, na IES e em eventos como a Semana 
Acadêmica das Licenciaturas, com a participação dos residentes como ouvintes e nos I e II Encontro do Programa de Residência Pedagógica da Unimes divulgados aos interessados no portal da Universidade.

\section{A importância do estágio supervisionado através do Programa de Residência Pedagógica na formação do professor de Geografia}

O estágio supervisionado compõe parte dos elementos de identidade de um curso de graduação em licenciatura. É de fundamental relevância que o estagiário perceba a relação do tripé que envolve as atividades de extensão, pesquisa e ensino e sua intersecção com as atividades do estágio. A importância do Programa de Residência Pedagógica (PRP) desperta no residente a importância da escola-campo e destaca o estágio supervisionado como um dos momentos de compreensão da relação teoria e prática.

O aporte teórico que sustenta nossa análise sobre a importância do estágio supervisionado na formação de licenciandos está pautado em Giglio et al. (2011) e Passini (2010). Além da linguagem acadêmica foi necessário discutir com os alunos a interpretação das resoluções, como a Resolução CNE/CP 2, de 19 de fevereiro de 2002 e a Resolução $n^{\circ} 2$, de $1^{\circ}$ de julho de 2015, para que reconheçam a importância dos direitos e deveres em relação à comunidade escolar envolvida e à Universidade. Outra leitura concomitante às mencionadas diz respeito à Base Nacional Comum Curricular (BNCC) sobretudo quanto às descrições das Competências Gerais, das que envolvem ás áreas do conhecimento e dos componentes curriculares relativos a atuação dos estagiários. Em virtude de seu caráter normativo, a Base é um documento que deve articular seus indicadores com o currículo da rede onde o aluno vivencia tal prática. Desde 2019, a rede municipal de ensino de São Vicente promove a análise e implementação da BNCC oferecendo formação aos professores.

Durante nossa participação neste Programa corroboramos com as ideias de Passini (2010) quando apresenta inquietações e a busca por respostas sobre a prática do estágio supervisionado em Geografia: 
Será o estágio, na forma como tem sido realizado, uma experiência significativa e construtiva para os futuros professores de Geografia? Que crescimento os estagiários conseguem ter com nossas experiências em sala de aula? Qual o significado de estágio da Prática de Ensino de Geografia para professores e alunos da educação básica? Por que a experiência de estágio parece desmotivadora para muitos estagiários e alunos? (PASSINI, 2010, p. 17)

Todo o percurso de participação dos estudantes foi apresentado através de reuniões realizadas na Universidade e escola-campo junto aos preceptores. Esta integração com a escola resultou em uma experiência de grande aprendizado aos residentes.

A vivência dos residentes em uma escola pública da rede municipal de ensino de São Vicente promoveu o contato com a realidade do modelo implementado pela Secretaria de Educação (Seduc), da gestão da unidade de ensino e da prática docente através da preceptora. É oportuno registrar todo o empenho da Seduc em promover a participação da Universidade na dinâmica da escola. A Unimes recebeu apoio de vários gestores que participaram assiduamente das atividades promovidas tanto na escola-campo, quanto na instituição. Esta integração e afetividade foi de grande importância aos resultados obtidos ao finalizarmos o programa em janeiro de 2020.

Giglio et al. (2011) demonstra a importância do acesso de estudantes em formação para a carreira docente quando estagiam em escolas públicas:

As escolas, em especial as pertencentes às redes públicas de ensino, são campos privilegiados de aprendizagem prática das instituições formadoras de professores em nível superior por serem lugares característicos da diversidade e onde os saberes profissionais se desenvolvem. (GIGLIO et al., 2011, p.24).

Em todo o processo o incentivo a formação de residentes envolvidos com a pesquisa foi promovido pelas docentes orientadoras durante a formação na universidade. Com o propósito da construção crítico-reflexiva o papel do professor pesquisador foi reforçado para que a elaboração de uma prática adequada e criativa ocorresse a partir da apropriação do conteúdo quanto às 
normativas documentais da BNCC, do programa de ensino da unidade e do Projeto Pedagógico do Curso de licenciatura.

Os relatos dos participantes do processo mostram a necessidade de que programas como este sejam permanentes para agregar metodologias, técnicas e suporte teórico na formação dos licenciandos.

\section{Percurso Metodológico: a experiência dos residentes de Geografia no subprojeto Multidisciplinar}

Este relato de experiência partiu da vivência de dois residentes, que chamaremos de relato de Residente 1 e Residente 2, na época estudantes de graduação de Geografia na modalidade presencial. Estes alunos, hoje egressos da Universidade, desenvolveram no percurso universitário um perfil voltado para pesquisa. Participaram de projetos de Iniciação Científica com bolsa do Programa de Iniciação Científica financiado pela Unimes, participaram do Encontro de Pesquisa e Iniciação Científica (EPIC/2019) na universidade e vivenciaram as saídas de campo promovidas no curso de Geografia. O bom desempenho no PRP despertou em ambos a motivação para cursarem uma segunda licenciatura junto ao curso de Pedagogia da instituição. Atualmente, são professores de ensino básico na rede privada e pública de São Vicente e ambos consideram a experiência do PRP um divisor de águas para as atuações docentes que passaram a exercer.

A proposta de apresentação deste relato se fará por pares, ou seja, as transcrições apresentadas contêm as impressões destes dois residentes. Dividimos a narrativa dos alunos em alguns temas, como: a localização da unidade de ensino; a acolhida da preceptora - sempre presente em todo o processo e disposta a colaborar em cada etapa planejada -; a importância da apropriação sobre as teorias que envolvem a Aprendizagem Significativa e sua relação com os componentes do subprojeto multidisciplinar: Geografia, História, Matemática e Pedagogia.

Nesta primeira citação, os residentes comentam as pesquisas realizadas sobre a localização, vulnerabilidade socioambiental e cultural da comunidade e textos sobre a participação da comunidade sobre a importância e conteúdo do 
Projeto Político Pedagógico da escola. Esta etapa foi sustentada por leituras do material de Veiga (1998) e Severino (2006).

Além de conhecemos algumas das instalações internas e externas da escola, investigamos sua história e descobrimos que sua criação é recente com apenas 18 anos. Sua construção foi realizada e incentivada por um pastor que atuava na comunidade do bairro. Hoje a escola atende alunos de outros setores da cidade por ser a única daquela região a oferecer aulas para o ensino fundamental I e II.

Localiza-se em uma região periférica de São Vicente, no bairro chamado Náutica III, com uma boa estrutura para sua localidade, atendendo relativamente bem à demanda social da comunidade.

Consideramos oportuno destacar os dados do Índice de Desenvolvimento da Educação Básica (IDEB). Este índice reúne os resultados de dois conceitos igualmente importantes para a qualidade da educação: o fluxo escolar e as médias de desempenho nas avaliações e, observamos que os dados da Escola no ano de 2015 estava abaixo da meta assim como em 2013. Assim, pudemos observar que havia uma necessidade da atuação do Projeto de Residência Pedagógica, para que assim pudéssemos ter uma atuação mais eficaz com relação às necessidades das instituições escolares, colaborando com a melhor qualidade de ensino. Este tipo de análise foi possível em virtude da formação recebida na Universidade pelos professores orientadores dos subprojetos (RESIDENTES 1 e 2, 2019).

A preceptora marcou de forma efetiva a participação dos residentes na escola. Vale salientar que participou de todas as atividades planejadas durante os dezoito meses, estando presente nas reuniões realizadas na Unimes junto aos supervisores, colaborando quando gestores da Secretaria de Educação de São Vicente participavam das reuniões com a Coordenadora Institucional e docentes orientadoras do projeto, bem como nos projetos realizados na escola como o Programa Leia São Vicente além de transmitir sua experiência nos dois eventos promovidos pela instituição para apresentar os resultados do programa em 2018 e 2019.

Sobre a preceptora que nos acolheu para a realização do subprojeto e a realização da regência mantivemos uma relação produtiva. A professora preceptora, teve sua graduação na Universidade Católica de Santos, cursando Licenciatura em Geografia, mas não é a sua primeira formação superior. Formou-se em Administração e migrou para área da educação. 
Além de lecionar na no período da manhã, também atua em outro colégio no período da tarde no município de Santos. Seu perfil de docente se resume em uma pessoa reflexiva sobre a rotina dos docentes. É uma profissional bem competente, respeitada entre os alunos e colegas de trabalho, cumpre com seu dever atentando-se sempre às particularidades das turmas e alunos, fazendo sempre o possível para atender às demandas.

Todo o processo da regência foi realizado sob a supervisão da preceptora. Durante a ambientação tivemos contato com os planos de curso de Geografia e História para nós apropriamos do conteúdo a ser discutido (RESIDENTES 1 e 2, 2019).

Reforçamos que os gestores da unidade de ensino, durante todo o percurso do projeto, contribuíram de forma produtiva abrindo a escola para o acesso dos residentes e promovendo discussões sob a orientação da coordenadora pedagógica. Nestas reuniões, sempre contamos com a presença da preceptora.

Vale destacar, que os funcionários da escola foram atenciosos e nos proporcionaram uma recepção calorosa todos os dias que chegávamos na regência. Ensinar as crianças foi o nosso maior desafio para desenvolver a troca de saberes e elaboração de cada atividade proporcionada (RESIDENTES 1 e 2, 2019).

Em todo o processo de ambientação e formação na Universidade procuramos nos envolver em leituras direcionadas às teorias que envolvem a Aprendizagem Significativa e as áreas de conhecimento da BNCC e dos cursos envolvidos no subprojeto Multidisciplinar.

Procuramos em todo o processo da regência realizar leituras sobre Aprendizagem significativa e aplicar nas aulas dialogadas. A formação com os docentes coordenadores na UNIMES colaborou para organizarmos nossas aulas dialogadas e investigar o conhecimento prévio dos alunos sobre os temas abordados (RESIDENTES 1 e 2, 2019).

A denominação "Teoria da Aprendizagem Significativa" identifica as propostas sobre a aprendizagem escolar e a instrução formuladas pelo psicólogo norte-americano D.P. Ausubel. As ideias de Ausubel, cujas formulações iniciais são dos anos 60 do século $X X$, encontram-se entre as primeiras propostas psicoeducativas que tentam explicar a aprendizagem escolar e o ensino a partir de um marco distanciado dos princípios condutistas 
(estímulo-resposta), tendo, em troca, uma perspectiva cognitiva sobre esses processos.

As proposições de Ausubel partem da consideração de que os indivíduos apresentam uma organização cognitiva interna baseada em conhecimentos de caráter conceitual, sendo que a sua complexidade depende, muito mais que do número de conceitos presentes, das relações que esses conceitos estabelecem entre si. Entende-se que essas relações têm caráter hierárquico, de maneira que a estrutura cognitiva é compreendida, fundamentalmente, como uma rede de conceitos organizados hierarquicamente de acordo com o grau de abstração e de generalização.

A aprendizagem significativa implica, como um processo central, a interação entre a estrutura cognitiva prévia do aluno e o material ou conteúdo de aprendizagem. Essa interação traduz-se em um processo de modificação mútua tanto da estrutura cognitiva inicial como do material que é preciso aprender, constituindo o núcleo da aprendizagem significativa.

A noção de aprendizagem significativa, definida dessa maneira, torna-se nesse momento o eixo central da teoria de Ausubel. Efetivamente, a aprendizagem significativa tem vantagens notáveis, tanto do ponto de vista do enriquecimento da estrutura cognitiva do aluno como do ponto de vista da lembrança posterior da utilização para experimentar novas aprendizagens, fatores que a elegem como a aprendizagem mais adequada para ser promovida entre os alunos.

Segundo a teoria de Ausubel, na aprendizagem significativa há três vantagens essenciais em relação à aprendizagem memorística. Em primeiro lugar, o conhecimento que se adquire de maneira significativa é retido e lembrado por mais tempo. Em segundo lugar, aumenta a capacidade de aprender outros materiais ou conteúdos relacionados de uma maneira mais fácil, mesmo se a informação original for esquecida. Em terceiro lugar, quando esquecida, facilita a aprendizagem seguinte - a "reaprendizagem".

A Base Nacional Comum Curricular (BNCC) está organizada através dos princípios éticos, estéticos e políticos - assegurados pelas Diretrizes Curriculares Nacionais - que visam a formação humana em suas múltiplas 
dimensões e a construção de uma sociedade justa, democrática e inclusiva. $\mathrm{O}$ documento visa a formação integral do estudante, seu crescimento como cidadão e sua qualificação para o trabalho. É um documento que determina os aspectos fundamentais que organizam cientificamente o que todos os alunos devem aprender durante a educação básica - do ensino infantil ao ensino médio - ano a ano, independentemente do local onde residem ou estudam. Todos os currículos das redes de ensino públicas e particulares de áreas rurais e urbanas do país deverão conter esses conteúdos.

A colaboração da BNCC para a educação diz respeito a concepção de educação integral - que é diferente de ensino em tempo integral - no qual contempla todas as dimensões do desenvolvimento humano, ou seja, a parte cognitiva, intelectual e o desenvolvimento físico, social, emocional e cultural. A proposta é o desenvolvimento de habilidades e atitudes, através da interdisciplinaridade e, não de forma isolada em cada componente curricular.

Sobre a participação dos pais e a comunidade identificamos algumas situações com base na reunião conduzida pela coordenadora pedagógica da escola. Segundo o relato, a participação dos pais declinou nos últimos anos. A presença na escola foi constante até o ano de 2012 e, após este período, a participação dos pais manteve-se em declínio até 2018, data que tivemos acesso a esta informação.

A pesquisa de Paro (2004) apresenta alguns elementos sobre a participação da comunidade externa à unidade escolar. Segundo o autor, três condicionantes determinam esta participação: os econômicos e sociais, os culturais e os institucionais. Os econômicos e sociais apresentam a vulnerabilidade econômica da comunidade. Quando o grupo possui condições materiais, disponibilidade de integração com projetos na escola e tempo este condicionante pode ser uma resposta da participação comunitária. O segundo condicionante diz respeito ao aspecto cultural que envolve a visão de mundo da comunidade em relação a viabilidade da participação, situações que estão diretamente relacionadas à vontade de integrar-se aos projetos escolares. $\mathrm{E}$, a terceira condicionante é a institucional que é favorecida quando o bairro ou região onde a escola se localiza possui "mecanismos coletivos" (PARO, 2004, 
p. 54), compreendidos como comitês de bairros, centro comunitário, sociedade de amigos de bairro, favorecendo ações que integrem as atividades da escola.

Durante as reuniões com os preceptores do subprojeto e a coordenação pedagógica descobrimos que a escola tinha uma participação mais ativa dos pais até o ano de 2012 quando a escola atendia somente os alunos do bairro. Mas com a chegada de novos alunos do bairro vizinho, a participação dos pais tem diminuído deixando de participarem de muitos eventos e projetos da escola, como a horta, por exemplo. Além do desinteresse da participação da comunidade em atuar em conjunto com a escola, nos foi relatado que os moradores dos bairros vizinhos invadiram a escola e promoveram alguns furtos. O principal aconteceu no ano de 2017 quando nos finais de semana foram roubados desde ventiladores, lâmpadas e mantimentos que compunham a merenda das crianças, e assim a escola passou a ter custos que o município não arca para suprir as necessidades. Após muitas insistências da direção da escola junto aos órgãos responsáveis, conseguiram guardas noturnos para que não ocorressem mais assaltos. Além disso, foi necessária a instalação de grades nas janelas afim de evitar qualquer tipo de depredação do patrimônio e grades nos muros da escola (RESIDENTES 1 e 2, 2019).

Ainda sobre a participação dos pais, Rittes (2017) propõe a gestão democrática como um dos alicerces para a relação nas instituições. Para essa autora "a realização de ações, projetos e práticas interativas englobando os pais dos alunos, são iniciativas que podem ajudar a reverter ou amenizar a crise pela qual passa a educação" (RITTES, 2017, p. 87).

Decorrente deste contato com a coordenadora pedagógica e a mediação da preceptora tivemos acesso a um projeto em andamento e normativo da rede municipal chamado Projeto Movimento Leia São Vicente, o projeto de revitalização da horta e a sala de informática da escola.

A escola, desenvolveu no ano letivo de 2018 o Projeto Movimento Leia São Vicente. Esta proposta tem como objetivo o estímulo de diferentes linguagens. Na escola a opção de desenvolvimento artístico foi direcionada para uma exposição de arte além de música e dança. O projeto da Horta foi iniciado no ano 2000, mas em virtude da mudança da gestão escolar e do perfil dos alunos o projeto foi abandonado. Os residentes se mobilizaram junto com a coordenadora pedagógica da escola para retomarem o projeto junto aos alunos. Sob a mediação da nossa preceptora tivemos o contato com a sala de informática. A sala de informática fez parte do projeto Castelinho, parceria entre o SENAI e as escolas municipais nos anos 2000. O 
objetivo era a aplicação de aulas teóricas e práticas de informática. Porém o projeto não foi adiante. Hoje, a sala funciona como um laboratório com sala de vídeo onde mais da metade dos computadores estão quebrados e não possuem internet (RESIDENTES 1 e 2, 2019).

Encerramos este relato de experiência sobre nossa participação no I Simpósio do Programa de Residência Pedagógica da Unimes.

O I Simpósio do programa de residência pedagógica da UNIMES 12/12/2018 foi realizado no intuito de que todos os residentes e preceptores pudessem socializar as experiências vividas durante o primeiro semestre do Programa de Residência Pedagógica.

O simpósio começou com uma fala da nossa coordenadora institucional, destacando a importância do projeto para nossas vidas como profissionais da educação e de quanto estamos sendo privilegiados por estamos saindo do modo tradicional e inovando para na formação teórica e prática. Destacou a importância do projeto para a Universidade e o incentivo à pesquisa. Destacou também o desenvolvimento do projeto e seus subprojetos.

Em seguida, ouvimos os docentes orientadores da instituição explicando os subprojetos e seus objetivos e como foi a experiência de vivenciar e trocar conhecimento com as preceptoras juntamente com as escolas que nos acolheram e atenderam todas as expectativas. Logo após, foi a vez de cada preceptora relatar como foi a experiência de trabalhar neste subprojeto, mostrando a importância de nos receber na sala de aula, dividindo o seu espaço e conhecimento com os residentes e de quanto foi importante para sua profissão. Relataram que esta experiência, elas não tiveram durante a sua formação e valorizaram a educação brasileira sempre com um olhar de esperança de que dias melhores virão e que novos pesquisadores, cientistas e doutores sairão das escolas públicas porque somos capazes de fazer a diferença na vida de cada um daqueles alunos

E, para finalizarmos o encontro, nós os residentes, contamos o quanto foi produtivo cada momento deste projeto, começando pelas reuniões com os professores orientadores na Instituição que nos acolheram e desenvolveram atividades que foram de extrema importância para o nosso momento de experiência da regência na escola (RESIDENTES 1 e 2, 2019).

As impressões relatadas pelos residentes serviram como recurso para publicação de resultados deste material e dos que pretendemos desenvolver sobre a formação do aluno no processo de construção do Programa. No final do ano de 2019, organizamos várias reuniões com todos os residentes e 
preceptores e desenvolvemos a metodologia sobre grupo focal para termos acesso às percepções dos envolvidos. Este material será compilado para futuras publicações.

\title{
Resultados e Discussões observados nos relatos de experiência
}

Através do relato de experiência dos residentes concluímos ter atingido os objetivos do programa. A percepção dos residentes quanto ao distanciamento das teorias em relação às práticas ficou evidente em vários momentos transcritos no relato. O programa desenvolvido pela Capes é de fundamental importância para a formação de professores para aprenderem a promover essa integração e desenvolver técnicas inovadoras e criativas a partir das metodologias apresentadas nos compêndios acadêmicos.

\begin{abstract}
A experiência de estarmos visitando uma escola foi extremamente rica e satisfatória, pois nos permitiu aproximação da realidade e das dificuldades que uma escola pública tem durante o cotidiano. Constatamos que as teorias estudadas na sala de aula da universidade se divergem e muito da prática de uma sala de aula e de todos os problemas presentes na educação brasileira. Constatei que 0 planejamento de aula não é somente um momento burocrático, mas deve ser um momento de reflexão que interpreta realidades, favorece condutas mais apropriadas e proporciona melhores resultados nas diversas situações educacionais. Foi possível compreender por experiência o que já tinha sido passado durante a preparação: que os planos de aula devem levar em consideração o tempo disponível para o alcance dos objetivos relacionados com os conteúdos não deixando em segundo plano a realização das atividades. O exercício deste projeto serviu-me também para demonstrar como a responsabilidade, de nós futuros educadores, é importante para a formação e desenvolvimento de novas e inteligentes maneiras de construir conhecimentos, com a compreensão de que cada aluno é único (RESIDENTES 1 e 2, 2019).
\end{abstract}

Durante o processo de formação dos residentes na universidade, desenvolvemos várias estratégias de articulação entre a BNCC e o plano de curso dos componentes curriculares na escola-campo. A participação da preceptora foi fundamental nesta articulação. Os alunos criaram sequencias didáticas, trabalharam com diferentes linguagens seguindo as orientações da instituição e da preceptora. 
As discussões dos conceitos referentes à Aprendizagem Significativa foram articuladas durante a formação dos residentes de forma contínua. Os pressupostos teóricos foram estudados pelos residentes e articulados durante a regência.

Durante as orientações junto aos docentes orientadores articularam-se os documentos normativos, como a Base, o Projeto Político Pedagógico da escola, o Projeto Pedagógico da Graduação em Geografia e o planejamento organizado no Programa. Esta articulação foi estrategicamente organizada para que o residente percebesse o contexto da implementação do conteúdo destes materiais.

Para concluirmos nossa discussão é oportuno destacar as impressões da residente 2 sobre a importância do Programa:

O Projeto de Residência Pedagógica pode me proporcionar o alinhamento da teoria com a prática. Neste processo, aperfeiçoei a minha postura frente a uma sala de aula, além da elaboração de conteúdos e administração do tempo. Consegui obter uma boa base da realidade educacional do país, afirmando minha esperança na educação pública de qualidade e na diferença que o educador faz na vida dos alunos e da comunidade em geral. A realidade vivenciada proporcionou grandes trocas com os alunos, professores e funcionários da escola, possibilitando a oportunidade de lecionar e aprender com cada um dos participantes. Pudemos aplicar o que aprendemos sobre Aprendizagem Significativa acompanhando e mediando todas as fases até a assimilação. O projeto proporcionou um aprofundamento do senso crítico referente a estrutura da escola e os recursos disponibilizados pelo governo (RESIDENTE 2, 2019).

O residente 1 finalizou suas considerações sobre o programa promovendo reflexões sobre a importância e a oportunidade de participar do Programa,

O projeto residência pedagógica foi sem dúvida alguma uma experiência que nos fez colocar em prática $o$ que as universidades têm construído de uma excelente qualidade a teoria. Mas o que é a teoria na vivência do dia a dia? Foi o que pude descobrir em cada fase desta etapa que conclui neste semestre. Começando pela formação da residência onde os docentes orientadores nos apresentaram uma proposta do projeto e detalharam de uma forma abrangente durante as reuniões tudo o que precisaríamos saber sobre o que é um professor em sala de aula e qual a sua função quanto docente 
na vida de cada aluno. Os relatos de suas próprias experiências quando atuaram em escolas públicas nos aproximou mais ainda da realidade que encontraríamos quando chegássemos a escola núcleo da residência. Todas as reuniões de desenvolvimento para contribuição na elaboração e desenvolvimento de documentos foram de extrema importância para a construção e raciocínio para o nosso desenvolvimento quanto docente na nossa vida acadêmica daqui para frente. A experiência de estarmos visitando uma escola foi extremamente rica e satisfatória, pois nos permitiu aproximação da realidade e dificuldades que uma escola pública tem durante o cotidiano. Constatamos que as teorias estudadas na sala de aula da universidade se divergem e muito com a prática de uma sala de aula e todos os problemas presentes na educação brasileira. Com a realização deste estágio foi possível adquirir mais confiança na prática pedagógica. (...) Pude perceber a real importância em despertar nos alunos a criticidade e de quanto eles devem desenvolver e sempre questionar durante as aulas os temas abordados e fora da sala de aula a sua relação com o mundo, sua condição humanam tendo assim, uma perspectiva de que estão sendo formados cidadãos mais completos, com opinião, conhecimento e atitude. (RESIDENTE 1, 2019).

$\mathrm{Na}$ descrição da percepção dos residentes sobre o programa fica evidente que o discurso, além de apresentar a carga emotiva também destaca a construção do raciocínio geográfico quando registram a importância da construção de um aluno com pensamentos críticos e reflexivos sobre a leitura que passam a enxergar do mundo. Este mundo varia de escalas e subjetividades, indo da micro para a macro interpretação.

\section{Considerações Finais}

A partir dos relatos dos residentes concluímos que atendemos o objetivo geral deste projeto que propôs o aperfeiçoamento da relação entre a teoria e a prática dos alunos na escola e a consequente formação dos professores. Este processo fica explícito nas análises feitas pelos residentes ao destacarem suas impressões sobre o distanciamento que muitas vezes ocorre entre a realidade escolar e as teorias pedagógicas - construídas em alguns momentos por pesquisadores que não vivenciam o "chão da escola" - se distanciam da realidade. 
A Aprendizagem Significativa, teoria que balizou o subprojeto multidisciplinar, promoveu aos residentes uma apropriação do conteúdo e aplicação tanto no planejamento quanto nas conexões feitas durante a regência, seja pela consulta à BNCC ou em conjunto com as teorias que envolvem o desenvolvimento do raciocínio geográfico.

A oportunidade de participação neste Programa, conforme apresentado neste material, foi apreciada por todos os envolvidos agregando conhecimento e despertando nos residentes a importância da vivência na escola e a sistematização que envolve o estágio supervisionado.

Esperamos que este Programa continue oportunizando aos estudantes das licenciaturas a tomada de consciência da importância, necessidade e urgência na formação de professores na sociedade brasileira contemporânea.

Registramos nossos agradecimentos junto à Coordenação de Aperfeiçoamento de Pessoal de Nível Superior (CAPES) que oportunizou a participação da UNIMES junto ao Programa de Residência Pedagógica, assim como, a concessão de bolsas nas modalidades de residentes, coordenador institucional, docente orientador e preceptor.

\section{Referências}

AUSUBEL, David. P. Aquisição e retenção de conhecimentos: uma perspectiva cognitiva. Lisboa: Plátano Edições Técnicas, 2000.

BRASIL. Base Nacional Comum Curricular: Educação é a base. Disponível em:>http://basenacionalcomum.mec.gov.br/wp-content/uploads/2018/02/bncc20dez-site.pdf< < acesso em: 15 de set. 2020.

BRASILIA (DF). EDITAL CAPES nº 06/2018 (RETIFICADO). Chamada Pública para apresentação de propostas no âmbito do Programa de Residência Pedagógica. $2018 . \quad$ Disponível em:< https://www.capes.gov.br/images/stories/download/editais/27032018-Edital-6Residencia-Pedagogica-Alteracao-II.pdf> . Acesso em 16 de set. 2020.

GIGLIO, Célia Maria B.; BUNZEN, Clécio; SILVESTRE, Magali Aparecida; GOMES, Marineide de Oliveira; PINTO, Umberto de Andrade. Residência Pedagógica: diálogo permanente entre a formação inicial e a formação contínua de professores e pedagogos. In: GOMES, Marineide de Oliveira (orgs.). Estágio na Formação de Professores. Possibilidades formativas entre ensino pesquisa e extensão. São Paulo: edições Loyola, 2011. 
MOREIRA, Marco A. Aprendizagem Significativa: Um conceito Subjacente. Aprendizagem Significativa em Revista/Meaningful Learning Review - V1(3), pp.25-46, 2011.

PARO, Vitor Henrique. Gestão Democrática da Escola Pública. São Paulo: Editora Ática, 2004.

PASSINI, Elza Yasuko. Prática de Ensino de Geografia e Estágio Supervisionado. São Paulo: Contexto, 2010.

RITTES, Rosemeire Silva. A adesão da família no processo educacional e os reflexos na escola. 2017. Dissertação (Mestrado Profissional em Práticas Docentes no Ensino Fundamental). Universidade Metropolitana de Santos, 2017.

SEVERINO, Antonio Joaquim. Fundamentos ético-políticos da educação no Brasil de hoje. In: LIMA, J.C.F., and NEVES, L.M.W., org. Fundamentos da educação escolar do Brasil contemporâneo [online]. Rio de Janeiro: Editora FIOCRUZ, 2006, pp. 289-320.

VEIGA, IIma Passos da. Projeto político-pedagógico da escola: uma construção coletiva. In: VEIGA, IIma Passos da (org.). Projeto político-pedagógico da escola: uma construção possível. Campinas: Papirus, 1998. p.11-35.

\section{Sobre os autores}

\section{Rafael da Rocha Lopez}

raffa-lopez@hotmail.com

Graduado em Licenciatura em Geografia pela Universidade Metropolitana de Santos (UNIMES) de 2016 a 2018. Possui segunda licenciatura em Pedagogia pela UNIMES (2019). Foi bolsista do Programa de Iniciação Cientifica, entre 2017 e 2018, com a pesquisa "Geografia e Paisagem: O estudo dos vínculos que os moradores têm com os canais de drenagem do projeto de Saturnino de Brito". Participou como bolsista do Programa de Residência Pedagógica da UNIMES edital 06/2018. Publicou capítulo no livro "Geografia no Século XXI Volume 4" da editora Possion intitulado "Geografia, percepção e topofilia: Relações e significados entre os moradores e visitantes da cidade de Santos (SP) com os tradicionais canais de Saturnino de Brito". Atualmente é professor das redes estadual e particular em São Vicente, SP.

\section{Paula Vitória de Farias Santos}

paulavitoriast@gmail.com

Graduada em Licenciatura em Geografia pela Universidade Metropolitana de Santos (UNIMES) de 2016 a 2018. Possui segunda licenciatura em Pedagogia (UNIMES) em 2019. Bolsista do Programa de Residência Pedagógica da UNIMES pelo edital 06/2018. Participou do III Colóquio Espaço e Economia: Transformações no capitalismo mundial e a produção social do espaço: novos arranjos territoriais e a economia política do desenvolvimento, em 2019 pela 
Universidade do Estado do Rio de Janeiro (UERJ) com a apresentação oral intitulada "A precarização do trabalho e da qualidade de vida do trabalhador paulistano na redemocratização". Coautora no artigo intitulado "A precarização do trabalho e da qualidade de vida do trabalhador paulistano na redemocratização" na revista Espaço e Economia. Atualmente é professora da rede privada em São Vicente, SP.

\section{Renata Barrocas}

renata.barrocas@unimes.br

Doutora em Geografia (2005) pela Universidade Estadual Paulista (UNESP Rio Claro), Mestre em Geografia Física (2001) pela Universidade de São Paulo (USP) , Licenciada (1996) e Bacharel (1995) em Geografia pela Universidade Estadual Paulista (UNESP - Rio Claro). Docente permanente do programa de Mestrado Profissional em Práticas Docentes no Ensino Fundamental (UNIMES). Atualmente ministra aulas e pesquisa nas graduações de Geografia e Pedagogia (UNIMES) e no Ensino a Distância (EAD) na licenciatura em Geografia (UNIMES). Exerce supervisão de estágios na Licenciatura de Geografia (UNIMES). Participou de agosto/2018 a janeiro/2020 como docente orientadora do subprojeto Multidisciplinar junto ao Programa de Residencia Pedagógica (CAPES). Atua com pesquisa nas seguintes temáticas: ensino de Geografia , percepção e cognição do meio ambiente e turismo.

\section{Abigail Malavasi}

amalavas@uol.com.br

Possui graduação em Psicologia pela Universidade de Mogi das Cruzes (1980), graduação em Pedagogia pela Universidade Nove de Julho (1984), mestrado em Educação (Psicologia da Educação) pela Pontifícia Universidade Católica de São Paulo (1996) e doutorado em Doutorado em Educação pela Universidade Estadual de Campinas (2006). Foi diretora de escola do Governo do Estado de São Paulo de 1996 a julho de 2016. Atualmente é professora da graduação e do Mestrado Profissional Práticas Docentes no Ensino Fundamental da Universidade Metropolitana de Santos (UNIMES), bem como coordenadora do curso de Psicologia da mesma instituição. Tem experiência na área de Educação, com ênfase em gestão educacional e formação de professores, atuando principalmente nos seguintes temas: didática, avaliação e currículo, psicologia da aprendizagem e do desenvolvimento, inclusão escolar, letramento, alfabetização e formação continuada de professores.

\section{Mariangela Camba}

mariangela.camba@unimes.br

Graduada em Pedagogia pela Faculdade de Ciências, Educação e Letras Don Domênico (1981); Mestre em Educação (Educação e Currículo) pela Pontifícia Universidade Católica de São Paulo (2002); Doutora em Educação (Políticas de Avaliação) pela Universidade de Campinas em 28/07/2011. Atualmente é professora na graduação, pós-graduação lato sensu a distância e docente do Programa de Mestrado Profissional: Práticas Docentes no Ensino Fundamental da Universidade Metropolitana de Santos nas disciplinas Avaliação e as Práticas Interdisciplinares no Ensino Fundamental, Políticas Públicas 
Implementadas no Ensino Fundamental. Com experiência na área de Educação, Políticas Públicas de Educação e de Avaliação, temas relacionados à formação docente; prática- político - pedagógica; Coordenação do trabalho pedagógico; Currículo: teoria e prática; Didática; Gestão Educacional e Escolar e Avaliação Educacional e Institucional - formação docente educação - ensino e aprendizagem - políticas públicas de educação - políticas públicas de avaliação -organização - tempo-espaço - currículo e avaliação.

\section{Patrícia Lopes Barboza}

patricia-barboza@hotmail.com

Licenciatura e Bacharelado em Geografia pela Universidade Católica de Santos (2009). Pós-graduada em Ética, Valores e Cidadania na Escola pela Universidade de São Paulo (2014). Aperfeiçoamento em Educação Ambiental pela Universidade Federal de São Paulo (2015). Atuou como preceptora no Programa Residência Pedagógica pela Universidade Metropolitana de Santos (2018-2019). Desde 2010, exerce o cargo de Professora de Geografia na Prefeitura de São Vicente e na Prefeitura de Santos começou a atuar em 2017. 